\title{
DILEMA IDENTITAS KEBUDAYAAN DALAM TRADISI MA'TINGGORO TEDONG ALA SUKU TORAJA DI ERA TURISTIFIKASI
}

\author{
Hasni $^{1}$, Muhammad Ihsan Nur ${ }^{2}$, Nurul Fauziah ${ }^{3}$, Alif Purwanto ${ }^{4}$ \\ ${ }^{1234}$ Prodi Pendidikan IPS, Fakultas Ilmu Sosial, Universitas Negeri Makassar \\ hasni@unm.ac.id ${ }^{1}$,ihsannur780@gmail.com²
}

\begin{abstract}
ABSTRAK
Suku Toraja merupakan salah satu suku yang ada di Indonesia dengan budaya dan tradisi yang unik. Kebudayaan asli yang masih dimiliki suku ini menjadi daya tarik para wisatawan. Nuansa mistik yang melekat pada suku ini menjadi ciri khas yang membedakan suku ini dengan yang lain. Namun, yang menjadi masalah adalah hilangnya identitas pada suatu kebudayaan yang dipengaruhi oleh lingkungan seperti dijadikannya sebagai ojek wisata. Penulisan ini untuk menunjukaan dan menjelaskan betapa pentingnya menjaga kebudayaaan diera turistifikasi. Secara khusus ma'tinggoro tedong (pemotongan kerbau) ala suku Toraja adalah tradisi pada upacara adat kematian rambu solo' yang harus dijaga keberadaannya. Metode penulisan yang digunakan pada ini adalah penulisan secara tematik yaitu membahas permasalahan pokok sesuai dengan tema yang diangkat oleh penulis. Dahulu rambu solo' hanya boleh dilaksanakan oleh orangorang dari kasta bangsawan. Namun seiring berjalannya waktu, setiap orang boleh melaksanakan upacara ini selama mampu dan memiliki biaya. Hadirnya turistifikasi dalam suatu budaya tentunya membawa dampak tersendiri, hal itu tidak dapat ditolak tetapi dijalani dengan melakukan penyaringan sehingga suatu kebudayaan tetap eksis tanpa menggeser nilai-nilai sakral yang ada di dalamnya.
\end{abstract}

Kata kunci: Ma'tinggoro Tedong, Toraja, Kebudayaan, Turistifikasi.

\begin{abstract}
The Toraja tribe is one of the tribes in Indonesia with a unique culture and traditions. The original culture that this tribe still has is an attraction for tourists. The mystical nuance inherent in this tribe is a characteristic that distinguishes this tribe from others. However, the problem is influenced by the environment, such as making it a tourist attraction. Writing this is to show and explain how important it is to maintain the culture in the era of tourism. In particular, the Torajan style ma'tinggoro tedong (buffalo slaughtering) is a tradition in the traditional ceremony of death rambu solo 'which must be maintained. The writing method used in this is thematic writing, which discusses the main problems in accordance with the theme raised by the author. In the past rambu solo 'could only be carried out by people from the aristocratic caste. But as time goes by, everyone may carry out this ceremony as long as they can and have money. The presence of turistification in a culture certainly has its own impact, it cannot be denied but it can be done by filtering it so that a culture still exists without shifting the sacred values contained in it.
\end{abstract}

Keywords: Ma'tinggoro Tedong, Toraja, Cultural, Tustificcation.

\section{PENDAHULUAN}

Era globalisasi telah banyak terjadi proses kebudayaan yang ditandai dengan adanya kecenderungan wilayah-wilayah di dunia, baik geografis maupun fisik, menjadi seragam dalam format sosial, budaya, ekonomi, dan politik. Salah satu fenomena yang sangat terkait dengan globalisasi yang membawa keuntungan bagi masyarakat yang hidup di negara berkembang adalah pariwisata. Pariwisata budaya merupakan aktivitas yang memungkinkan wisatawan untuk mengetahui dan memperoleh pengalaman tentang perbedaan cara hidup orang lain, merefleksikan adat istiadatnya, tradisi religiusnya, dan ide-ide intelektualnya yang terkandung dalam warisan budaya yang belum dikenalnya. 
Suku Toraja merupakan salah satu suku yang ada di Indonesia dengan budaya dan tradisi yang unik. Kebudayaan asli yang masih dimiliki suku ini menjadi daya tarik para wisatawan. Nuansa mistik yang melekat pada suku ini menjadi ciri khas yang membedakan suku ini dengan yang lain. Salah satu tradisi yang masih sakral keberadaannya adalah pemotongan kerbau dengan cara satu kali tebasan atau biasa disebut ma'tinggoro tedong.

Ma'tinggoro tedong sebagai tradisi yang awalnya sakral mengalami pergeseran fungsi dan pemaknaan ketika berhadapan dengan wisatawan. Dampak pariwisata terhadap lingkungan penerima dimana suatu tradisi dan budaya dalam masyarakat dijadikan sebagai produk pariwisata yang disebut turistifikasi. Selain itu membicarakan pariwisata terkait erat dengan ekonomi dan pariwisata sebagai suatu industri jasa. Turstifikasi hadir sebagai industri pariwisata, relasinya dengan kebutuhan untuk mengonsumsi penduduk asli dan kebudayaan-kebudayaan mereka sebagai suatu trend global.

Tradisi ma'tinggoro tedong ketika dilihat dari tujuan aslinya adalah tuntunan agama atau aluk todolo dalam melakukan upacara kematian, tetapi seiring berjalannya waktu tradisi ini dimaknai sebagai tatacara untuk membagi kehidupan terhadap orang lain atau pihak keluarga dan kerabat yang telah meninggal agar dapat memberikan persembahan yang terbaik. Meski banyak kecaman dari beberapa pihak diluar Toraja utamanya pecinta binatang mengenai tradisi ini, namun bagi orang Toraja cara ini adalah cara turun-temurun yang tidak bisa diubah. Turistifikasi pada hakekatnya tidak bisa ditolak dan tentu saja mengarah pada turistifikasi kebudayaan sejalan berkembangnya pariwisata, hal ini akan menyebabkan terjadinya pergeseran kebudayaan itu sendiri dimana nilai-nilai sakral yang ada pada suatu tradisi utamanya ma'tinggoro tedong hilang secara perlahan karena dijadikan sebagai objek wisata. Hal itu dapat dilihat dari beberapa kasus dimana kerbau yang di tinggoro atau disembelih tidak mati dalam satu kali tebasan padahal seharusnya hanya satu kali tebasan, hal ini berdampak pada bergesernya nilai dan keutamaan budaya tersebut.

Berpacu pada hal-hal di atas maka penulis tertarik untuk melakukan penulisan dengan tema "Dilema Identitas Kebudayaan dalam Tradisi Ma'tinggoro Tedong Ala Suku Toraja di Era Turistifikasi" dengan menelaah dan menganalisis permasalahan pokok dari topik yang diangkat. Maksud dan tujuannya memberikan informasi bagi masyarakat mengenai pentingnya melestarikan budaya dan tradisi utamanya ma'tinggoro tedong pada masyarakat suku Toraja sehingga diharapkan dapat meningkatkan perekonomian masyarakat setempat tanpa mengurangi nilai-nilai sakral yang ada di dalamnya. Manfaat yang akan datang diperoleh dari penulisan ini adalah sebagai masukan bagi pemerintah untuk ikut andil dalam menjaga kelestarian kebudayaan seperti ma'tinggoro tedong agar tidak terjadi dilema terhadap identitasnya sebagai suatu tradisi, dengan adanya artikel ini diharapkan memberikan pengetahuan kepada masyarakat tentang makna dan tujuan dari ma'tinggoro tedong di tengah turistifikasi, dan bahan informasi dalam menambah pengetahuan bagi yang ingin mendalami mengenai budaya dan tradisi lokal utamanya ma'tinggoro tedong. 


\section{METODE PENELITIAN}

Metode penulisan yang digunakan adalah penulisan secara tematik. Penulisan tematik adalah metode untuk mengidentifikasi, menganalisis, dan melaporkan pola-pola atau tema dalam suatu data. Oleh karena itu penulisan ini membahas permasalahan pokok sesuai dengan tema yang diangkat oleh penulis.

Teknik analisis data pada penulisan ini berdasarkan Polit dan Hungler dalam (Corc adalah sebagai berikut :

1. Mencari Kesamaan (Kompare) persepsi atau pandangan antara data-data yang ada pada suatu literatur untuk menemuka suatu informasi yang baru pada topik yang diangkat.

2. Mencari Ketidaksamaan (Contract) mencari perbedaan pada jurnal-jurnal yang sesuai topik agar dapat menjadi landasan kegiatan review.

3. Memberikan Pandangan (Criticize) pada suatu data sekunder yang telah didapatkan dengan peristiwa atau kejadian-kejadian yang ada sekarang.

4. Membandingkan (Synthesize), agar yang dibuat diarahkan untuk menyusun kerangka pemikiran yang jelas tentang pemecahan masalah yang sudah diuraikan pada perumusan masalah.

5. Meringkas (Summarize) memberikan ulasan singkat tentang analisis yang telah dilakukan sebelumnya agar dapat memebrikan suatu informasi yang baru dan relevan tentang topik pembahasan yang diangkat.

Polit dan Hungler dalam Menurut (Cornwell ,2001) memberikan langkah-langkah penulisan dan teknik analisis data sebagai berikut :

\section{Bagan 1. Langkah-langkah Penulisan}
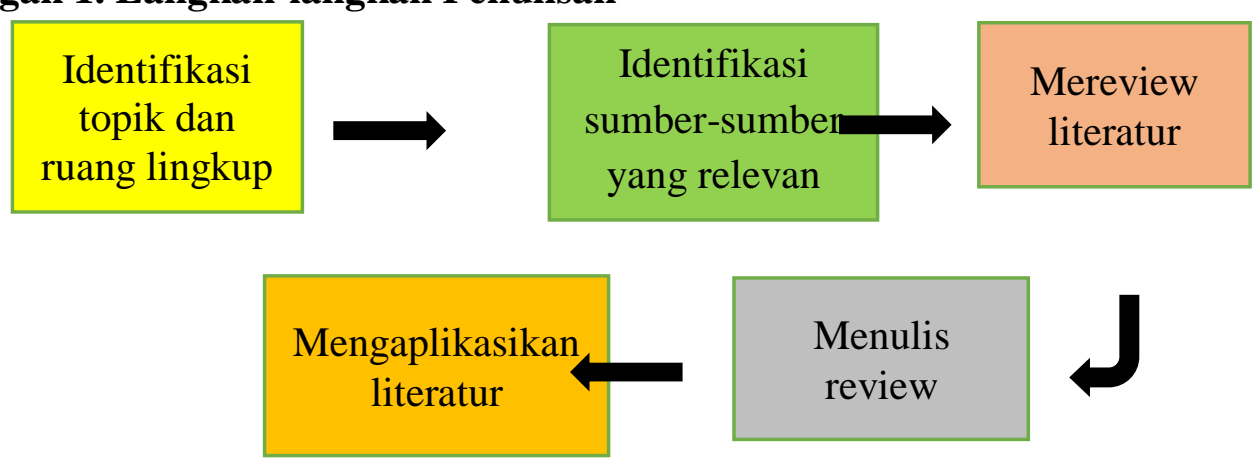

Sumber: (Carnwell,2001)

\section{HASIL PENELITIAN DAN PEMBAHASAN}

\section{Makna Tradisi Ma'tinggoro Tedong dalam Upacara Kematian Ala Suku Toraja Sebelum Era Turistifikasi}

Tedong sangat berharga bagi warga Toraja dibandingkan dengan jenis hewan yang lain. Bagi masyarakat Toraja tedong yang dikurbankan dalam jumlah banyak akan menjadi suatu kebanggaan tersendiri bagi keluarga yang bersangkutan untuk mempertahankan status sosial. Alasan mendasar kenapa orang Toraja harus melakukan ma'tinggoro tedong (pemotongan kerbau) dalam upacar rambu solo', karena orang Toraja begitu menghargai 
arwah para leluhur atau mereka yang telah lebih dulu meninggal. Pada poin inilah orang Toraja memiliki semacam keharusan untuk melakukan ma'tinggoro tedong (pemotongan kerbau) sebagai bentuk pemujaan tetapi juga sebagai bentuk penghargaan.

Dari data BPS Kabupaten Toraja Utara jumlah kerbau atau tedong yang dipelihara atau di ternakkan dari tahun ketahun relatif mengalami peningkatan. Hal ini tentunya berdampak pada prosesi adat di Toraja karena setiap acara kematian, kerbau adalah hewan yang sangat penting dalam upacara kematian. Hasil penelitian (Sirajuddin, Baba dan Andilolo, 2013) terdapat ilustrasi gambar mengungkapkan bahwa adanya kasus kematian masyarakat suku Toraja akan berbanding lurus dengan kebutuhan masyarakat terhadap kerbau sebagai bahan penting untuk melaksanakan acara kematian (Lihat Lampiran Gambar 1). Berikut adalah data kerbau yang diternak oleh masyarakat di Kabupaten Toraja Utara dari data (BPS 2020) Toraja Utara.

Tabel 1. Jumlah Hewan Kerbau yang di Ternak di kabupaten Toraja Utara Kabupaten Banyaknya Hewan yang Diternak

\begin{tabular}{cccccccccc}
\hline & \multicolumn{10}{c}{ Kerbau } \\
\hline Tahun & $\mathbf{2 0 1 8}$ & $\mathbf{2 0 1 7}$ & $\mathbf{2 0 1 6}$ & $\mathbf{2 0 1 5}$ & $\mathbf{2 0 1 4}$ & $\mathbf{2 0 1 3}$ & $\mathbf{2 0 1 2}$ & $\mathbf{2 0 1 1}$ & $\mathbf{2 0 1 0}$ \\
\hline $\begin{array}{c}\text { Toraja } \\
\text { Utara }\end{array}$ & 20796 & 21050 & 21002 & 18121 & 20582 & 20419 & 20157 & 19373 & 21464 \\
\hline
\end{tabular}

Sumber: Badan Pusat Statistik Kabupaten Toraja Utara

Terlihat pada tabel di atas bahwa jumlah kerbau yang diternak oleh masyarakat dari tahun 2010 sampai 2018 relatif konstan hanya pada tahun 2015 yang mengalami penurunan. Dari hasil telaah dan analisis peneliti bahwa jumlah kerbau yang diternak masyarakat Toraja sangat berdampak terhadap tatanan kehidupan masyarakat karena ditinjau dari aspek pelaksanaan upacara kematian tentunya semua membutuhkan kerbau yang banyak. Hal tersebut sesuai dengan penelitian yang dilakukan oleh (Mangopang, Widiarto, and Sunardi 2019) yang memberikan penilaian dari data lapangan yang sudah diolah (Lihat Lampiran Gambar 2) bahwa kerbau adalah hewan yang paling diminati masyarakat Toraja karena setiap upacara kematian di Tana Toraja pihak keluarga dan kerabat almarhum berusaha untuk memberikan yang terbaik, caranya adalah dengan membekali jiwa yang akan bepergian itu dengan pemotongan hewan, biasanya berupa kerbau dan babi sebanyak mungkin. Para penganut kepercayaan aluk todolo percaya bahwa roh binatang yang ikut dikurbankan dalam upacara kematian tersebut akan mengikuti arwah orang yang meninggal dunia tadi menuju ke puya (surga). Ma'tinggoro tedong dalam Bahasa Indonesia berarti "menyembelih kerbau". Kegiatan ini merupakan bagian dari rangkaian adat upacara kematian (rambu solo') di Toraja.

Dari analisis di atas dapat di ambil benang merah bahwa kerbau adalah hal yang paling sakral kaitannya dengan jumlah kerbau yang di ternakkan masyarakat ialah menjadi budaya tersendiri bagi masyarakat untuk melestarikan hewan yang dianggap spesial ini, selain itu peternakan kerbau juga menjadi sumber perekonomian masyarakat yang sangat menjanjikan karena tingginya permintaan pasar. 


\section{Dinamika Kebudayaan dalam Praktek Ma'tinggoro Tedong di Era Turistifikasi}

Tedong mengambil peran penting dalam tradisi yang berhubungan dengan agama purba atau yang sering dikenal oleh warga Toraja dengan sebutan aluk todolo. Tedong menjadi makna sebagai salah satu hewan persembahan dalam upacara rambu solo' karena warga Toraja percaya bahwa tedonglah sebagai jembatan untuk bisa ke Puya (surga bagi kepercayaan aluk todolo). Mantunu atau biasa disebut dengan ma'tinggoro tedong merupakan puncak pelaksanaan upacara pemakaman, yaitu dengan memotong hewan kurban. Ada beberapa hal yang perlu dianalisis dan ditelaah dalam dinamika kebudayaan dan praktek pemotongan kerbau untuk menjaga kelestarian suatu tradisi sekarang ini antara lain:

\section{a. Meningkatkan Pemahaman Kebudayaan pada Generasi Muda di Era Turistifikasi}

Minimnya budaya menulis pada masyarakat Toraja utamanya Toraja Utara di Sulawesi Selatan jadi ancaman tersendiri untuk kebudayaan setempat. Data BPS (Badan Pusat Statistik 2020) Kabupaten Toraja Utara dan grafik dari (KataData 2013) (Lihat Lampiran Gambar 3 dan Tabel 1) menyebutkan bahwa Kabupaten Toraja Utara tercatat sebagai kabupaten dengan jumlah melek huruf tertinggi, yakni mencapai $27,85 \%$ atau 34.344 jiwa, Data Dinas Pendidikan Sulsel menajabarkan bahwa sebaran angka penduduk tuna aksara di Sulawesi Selatan berada pada rentan usia 15-59 tahun, dengan cakupan antara 0,51-27 persen.

Dari data BPS dan Kata Data tersebut dapat dianalisis bahwa hubungan antara praktek kebudayaan dengan pendidikan dan literasi sangat berpengaruh karena tanpa disadari, perlahan cerita rakyat dan adat istiadat semakin tak dikenal generasi penerus. Lebih-lebih itu semua tak terdokumentasi. Penelitian yang dilakukan oleh (Guntara, Fatchan, and Ruja 2016) memberikan kesimpulan bahwa kebiasaan bertutur orang Toraja memebuat mereka tak punya dokumentasi warisan budaya, sehingga lambat laun akan ada perubahan dan pergeseran kebudayaan. Namun dibalik semua itu ada beberapa kegiatan yang dilakukan oleh pemerintah setempat dalam meningkatkan budaya literasi pada masyarakat sekarang ini seperti Festival Pena Toraja (Lihat Lampiran Gambar 4) dan berbagai festival semacamnya, hal ini sebagai upaya menjaga kebudayaan Toraja. Dalam festival tersebut anak dikenalkan dengan lingkungan dan keluarga. Mereka juga akan mengamati keadaan sekitar untuk membuat ide, setelah mengumpulkan ide anak baru diajari teknik menulis yang baik dan benar hal ini di lakukan untuk menjaga dan melestarikan kebudayaan.

\section{b. Pelestarian Tradisi Ma'tinggoro Tedong Berdasarkan Waktu Pelaksanaan}

Upacara adat rambu solo' Toraja merupakan upacara kematian masyarakat Toraja yang bertujuan untuk memberi penghormatan terakhir dan penyempurna kematian. Penelitian (Pasulu, Pilakoannu, and Lattu 2019) memberikan kesimpulan bahwa bagi orang Toraja seorang akan dianggap benar-benar meninggal setelah dilaksanakan upacara rambu solo' karena jiwa dan roh orang yang meninggal akan pergi bersama hewan telah disembelih. Dari hal tersebut dapat dianalisis bahwa besarnya peranan pelaksanaan kematian sehingga menjadi suatu kewajiban bagi keluarga dan sanak saudara untuk hadir 
dalam acara tersebut. Waktu ma'tinggoro tedong dalam upacara rambu solo' biasanya dilaksanakan sesuai dengan keinginan keluarga. Puncak upacara rambu solo' biasanya berlangsung pada bulan Juni sampai bulan Agustus, dan bahkan ada juga yang mengadakan pada bulan Desember. Alasannya cukup sederhana, agar keluarga yang ada di perantauan akan pulang untuk ikut dalam rangkaian acara tersebut apalagi bulan Desember biasanya di identikkan dengan hari libur.

Dari analisis di atas dapat dibuktikan dengan melihat data (BPS 2020) Kabupaten Toraja Utara tentang jumlah wisatawan mancanegara dan wisatawan nusantara yang berkunjung ke Toraja Utara dari tahun 2014-2018 (Lihat Lampiran Tabel 2 ) dimana terjadi peningkatan jumlah wisatawan yang berkunjung ke Toraja Utara pada bulan Juni sampai Desember. Dari tabel tersebut dapat dikaitkan bahwa adanya ketentuan bulan sebagai puncak pelaksanaan kegiatan adat menjadikan peluang bagi para wisatawan baik nusantara maupun mancanegara untuk hadir dan menyaksikan langsung pelaksanaan dan prosesi adat tersebut. Hal inilah cela terjadinya proses turistifikasi kebudayaan dan pergeseran makna kebudaya itu sendiri dimana nilai-nilai yang ada pada suatu tradisi utamanya ma'tinggoro tedong hilang secara perlahan karena dijadikan sebagai objek wisata meskipun sebenarnya turistifikasi kebudayaan tidak bisa ditolak oleh suatu masyarakat.

\section{Problematika Kebudayaan Suku Toraja di Era Turistifikasi.}

\section{a. Identitas Upacara Kematian dalam Penggunaan Tedong (Kerbau)}

Bagi kalangan bangsawan, tedong yang wajib dikurbankan sekitar lebih dari tiga ekor. Dari sekian banyaknya tedong tersebut ada satu jenis tedong yang wajib hadir dalam upacara tersebut yaitu tedong bulan atau dalam Bahasa Indonesia disebut "kerbau bule". Berdasarkan penelitian (Sadidan, Sulaeman, and Homzah 2015) yang mengklasifikasikan penggunaan kerbau berdasarkaan status pada upacara kematian di Toraja (Lihat Lampiran Tabel 3) dari tabel tersebut dapat dianalisis suatu persoalan bahwa terjadi perbedaan mencolok antara budak dan bangsawan dari segi jumlah kerbau yang digunakan dalam pelaksanaan upcara kematian hal ini sesuai dengan ketentuan ketentuan terdahulu bahwa dahulu rambu solo' hanya boleh dilaksanakan oleh orang-orang dari kasta bangsawan.

Namun seiring berjalannya waktu setiap orang boleh melaksanakan upacara ini selama mampu dan memiliki biaya. Pada masa kini tradisi upacara kematian biasa dilakukan dengan tidak lagi mengikuti aturan-aturan yang berlaku pada masa lalu. Hal ini tentunya berbeda dengan hasil penelitian yang dilakukan oleh (Rahmad 2018) yang menghasilkan tabel penggunaan kerbau dalam upacara kematian dilihat dari strata sosialnya (Lihat Lampiran Tabel 4) hasil penelitian tersebut berbeda dengan kondisi sekarang karena semakin tinggi strata sosial seseorang tidak dilihat dari pembagian yang dilakukan di masa lalu, tetapi strata sosial diukur dari semakin banyak kerbau yang dipotong (ma'tinggoro tedong).

Perkembangan zaman sekarang ini kemudian menitikberatkan arti strata sosial terutama pada kondisi ekonomi keluarga, sehingga strata sosial tidak bersifat tetap dalam melaksanakan tradisi ini. Karena siapapun dapat berusaha dan mampu memperbaiki kondisi ekonominya maka otomatis dapat menyumbangkan kerbau yang banyak dalam 
pelaksanaan ma'tinggoro tedong (penyembelihan). Dari pembahasan kerbau di atas tentunya memunculkan pertanyaan tentang tingkatan kerbau dan berapa harga kerba yang ada di Toraja. Penelitian yang dilakukan oleh (Sadidan, Sulaeman, and Homzah 2015) yang mengahsilkan tabel analisis tentang tingkatan kerbau Toraja yang diternakkan dan yang dibutuhkan dalam upacara kematian (Lihat Lampiran Tabel 5) dari tabel tersebut dapat kita ketahui bahwa harga kerbau tidak menjadi persoalan tetapi yang menjadi masalah saat ini adalah timbulnya rasa gengsi sebab terbukti bahkan untuk berusaha melakukan tradisi ma'tinggoro tedong mereka harus berhutang (pinjam) sesuai dengan harga kerbau, karena keadaan sudah mendesak. Padahal orang Toraja pada umumnya juga memelihara kerbau dan babi guna menyanggupi kewajiaban adat-istiadat setempat.

Akibat dari perkembangan zaman telah mewajibkan mereka untuk harus melakukan teradisi ini dengan konsekuensi berhutang dalam jumlah yang banyak dan dalam jangka panjang karena hutang ini dapat dibebankan kepada keturunan berikutnya dari hutang berasal dari prosesi ma'tinggoro tedong yang telah dilakukan dimasa lalu. Dari hal tersebut tergambar bahwa tradisi ini kemudian cenderung memperlihatkan motif lain selain menjalankan tradisi adat.

\section{b. Perubahan Makna dalam Tradisi Suku Toraja Pada Zaman Dulu dan Zaman Turistifikasi}

Upacara rambu solo' merupakan sebuah upacara yang sarat dengan nilai-nilai adat istiadat. Pada dasarnya hanya golongan bangsawan yang boleh melaksanakan upacara tersebut namun seiring perkembangan zaman siapa saja boleh melakukan asalkan mampu dari segi finansial. Tak heran jika jumlah kerbau yang dipotong begitu banyak yang pada akhirnya akan menjadi beban tersendiri bagi yang melaksanakan upacara adat karena tingginya harga jual kerbau saat ini tetapi semua dilakukan demi harkat dan martabat. Penelitian yang dilakukan (Matanasi, 2019) menghasilkan poster tentang rambu solo' yang mengalami pergeseran (Lihat Lampiran Gambar 5). Berikut bagan ilustrasi perubahanperubahan yang terjadi pada rambu solo':

\section{Bagan 2. Analisis perubahan Rambu Solo' Dulu dan Sekarang}

\begin{tabular}{|c|c|}
\hline & OLO' \\
\hline $\begin{array}{l}\text { Dulu } \\
\text { 1. Kaum bangsawan sudah } \\
\text { dianggap sah denagn hanya } \\
\text { membeli } 24 \text { ekor kerbau } \\
\text { 2. Masyarakat menghadiri } \\
\text { upacara mengenakan cawat \& } \\
\text { pakaian putih } \\
\text { 3. Jenazah diawetkan dengan } \\
\text { ramuann organic dari } \\
\text { tumbuhan }\end{array}$ & $\begin{array}{l}\text { Sekarang } \\
\text { 1. Banyak kasta non bangsawan } \\
\text { menyembelih >100an ekor } \\
\text { kerbau. } \\
\text { 2. Masyarakat menghadiri } \\
\text { upacara mengenakan pakaian } \\
\text { hitam (dipengaruhi orang- } \\
\text { orang Belanda) } \\
\text { 3. Jenazah diawetkan dengn } \\
\text { suntik formalin. }\end{array}$ \\
\hline
\end{tabular}

Sumber: Reportase \& riset Tirto.id 
Dari bagan di atas dapat dianalisis bahwa: Pertama, ditemukan kesan ada adu gengsi dalam mengadakan upacara tersebut hal ini dilakukan demi mengangkat status sosialnya. Kedua, pengaruh budaya dari luar tentunya mengubah tatanan pelaksanaan adat. Dan Ketiga, adalah perbedaan cara pengawetan jenazah yang dilakukan pada masa lalu dipengaruhi oleh kecanggihan teknologi saat ini.

\section{Membagun Perspektif Baru dalam Mempertahankan Kebudayaan dan Tradisi di Era Turistifikasi}

Potensi ekonomi pada suatu tradisi sebagai budaya lokal masyarakat sangat menjanjikan hal tersebut tertera dalam rincian realisasi retribusi objek wisata tahun 2018 yang dirilis oleh Disbudpar dan Bapenda Kab. Toraja Utara yang menunjukkan bahwa PAD Kabupaten Toraja Utara yang bersumber dari sektor pariwisata di tahun 2012 hingga Tahun 2018 rata-rata 2,3\%. Kontribusi paling besar yang diberikan oleh sector pariwisata yakni berada di tahun 2018 yaitu sebesar Rp. 2.668.600.000 atau sebesar 4,6\% (Lihat Lampiran Tabel 6).

Dalam menyikapi perkembangan zaman, masyarakat tentu harus berbenah dan siap dalam hal itu. Kebudayaan salah satu produk yang akan mengalami dan merasakan derasnya era globalisasi dan turistifikasi. Untuk itu perspektif masyarakat dalam melestarikan kebudayaan harus benar-benar dibangun dari sejak dini untuk membentengi perubahan budaya yang signifikan. Dalam hal ini berdasarkan berbagai analisis di atas dapat dibentuk perspektif dalam menjaga kebudayaan dalam menyikapi perkembangan zaman:

1. Hadirnya turistifikasi dalam suatu budaya tentunya membawa dampak tersendiri, hal itu tidak dapat ditolak tetapi dijalani dengan melakukan penyaringan sehingga suatu kebudayaan tetap eksis tanpa menggeser nilai-nilai yang ada di dalamnya.

2. Turistifikasi hadir sebagai bagian dari pariwisata, relasinya dengan kebutuhan untuk mengonsumsi penduduk asli dan kebudayaan-kebudayaan mereka sebagai suatu trend global yang sedang berkembang sekarang sehingga masyarakat perlu melaksanakan suatu upacara adat tanpa membawa suatu kepentingan sehingga upacara adat yang dilaksanakan nilai-nilai yang ada didalamnya tetap terjaga.

3. Karena pada dasarnya turistifikasi tidak bisa ditolak kedatangannya maka penulis menganalisis bahwa ini menjadi peluang sekaligus tantangan bagi masyarakat dan pemerintah, tugas kita adalah menjalankan kebudayaan dengan membawa identias suatu budaya agar nilai-nilai yang terkandung di dalamnya tetap terjaga disamping sebagai budaya dan tradisi yang menjadi objek bagi wisatawan.

\section{PENUTUP}

Ma'tinggoro tedong dalam Bahasa Indonesia berarti "menyembelih kerbau", tradisi ini merupakan salah satu rangkaian adat upacara kematian rambu solo di Toraja. Tedong menjadi makna sebagai salah satu hewan persembahan dalam upacara rambu solo' karena warga Toraja percaya bahwa tedonglah sebagai jembatan untuk bisa ke Puya (Surga bagi kepercayaan Aluk Todolo). Orang Toraja memiliki semacam keharusan untuk melakukan ma'tinggoro tedong (pemotongan kerbau) sebagai bentuk pemujaan tetapi juga sebagai 
bentuk penghargaan. Oleh karena itu jumlah kerbau yang diternakkan masyarakat cukup banyak karena telah menjadi budaya tersendiri bagi masyarakat untuk melestarikan hewan yang dianggap penting ini, selain itu peternakan kerbau juga menjadi sumber perekonomian masyarakat yang sangat menjanjikan karena tingginya permintaan pasar. Kebiasaan bertutur orang Toraja memebuat mereka tak punya dokumentasi warisan budaya, sehingga lambat laun terjadi perubahan dan pergeseran kebudayaan. Namun pemerintah setempat dalam meningkatkan budaya literasi pada masyarakat sekarang ini mengadakan kegiatan seperti Festival Pena Toraja. Seiring berjalannya waktu, setiap orang boleh melaksanakan upacara rambu solo' dan ma'tinggro tedong selama mampu dan memiliki biaya.

\section{DAFTAR PUSTAKA}

Badan Pusat Statistik [BPS]. 2020. Angka Melek Huruf Usia Lebih Dari 15 Tahun Kabupaten Toraja Utara 2011-2015: Badan Pusat Statistik Kabupaten Toraja Utara.

Badan Pusat Statistik [BPS]. 2020. Jumlah Wisatawan yang Berkunjung ke Toraja 20142018: Badan Pusat Statistik Kabupaten Toraja Utara.

Badan Pusat Statistik [BPS]. 2020. Jumlah Hewan Kerbau yang di Ternak di Kabupaten Toraja Utara 2010-2018: Badan Pusat Statistik Kabupaten Toraja Utara.

Cornwell, T Bettina, Isabelle Maignan, T Bettina Cornwell, and Isabelle Maignan. 2003. Carnwell, T. 2001. An International Review of Sponsorship Research. Journal of Advertisting. 21(1):1-21

Guntara, F., Fatchan, and Ruja, I. N. 2016. Kajian sosial budaya rambu solo' dalam pembentukan karakater peserta didik. Jurnal 15endidikan.

KataData. 2016. Angka Melek Huruf Usia Lebih Dari 15 di Kabupaten Toraja Utara Sulawesi Selatan 2010-2013. URL:https://databoks.katadata.co.id/datapublish/2016/05/12/angka-melek-huruf-usialebih-dari-15-di-kabupaten-toraja-utara-sulawesi-selatan-2010-2013. Diakses tanggal 3 Septemner 2020.

Mangopang, J., Widiarto, T. and Sunardi. 2019. Tedong sebagai syarat dalam upacara rambu solo' di Kecamaan Makale Kabupaten Tana Toraja. Jurnal KIP. 7 (3):18-24.

Pasulu, H. Y., Pilakoannu, R. T. and Lattu, I. Y. M. 2019. Dilema identitas pada pelaksanaan ma'pasillaga tedong dalam rangkaian ritual rambu solo. Pax Humana: Jurna Humaniora Yayasan Bina Darma. 6(1):21-34.

Matarasi, P. 2018. Beda rambu solo' dulu dan sekarang. Reportase \& riset Tirto.id: artikel sosial budaya.

Rahmad, A. 2018. Persepsi Masyarakat Terhadap Perubahan Budaya di Tanah Toraja (Studikasus Upacara Rambu Tuka'). Jurnal Enviromental Science. 1 (1):22-27.

Sadidan, I., Sulaeman, M. and Homzah, S. 2015. Faktor Sosial dan Budaya Kaitannya dengan Nilai Jual Kerbau: Kasus di Pasa Bolu, Kabupaten Toraja Utara, Provinsi Sulawesi Selatan. E-Journal Mahasiswa dan Pasca Sarjan Universitas Padjajaran. 4 (3):20:28.

Sirajuddin, S. N., Baba, S. and Andilolo. D. 2013. Beberapa Motivasi Masyarakat Toraja Memotong Ternak Kerbau pada Upacara Adat (Rambu Solo'dan Rambu Tuka'). Jurnal Ilmu dan Industri Peternakan 1(1):44-45. 